\title{
Role of radiology in COVID-19 pandemic and post COVID-19 potential effects on radiology practices
}

Currently, the world is experiencing the biggest healthcare crisis in modern history. A very contagious novel coronavirus SARS-CoV-2 has caused a pandemic initially started in Wuhan, China, and later spread to other countries and continents. At the moment more than five million people have been infected by SARS-CoV-2 globally and accounts for more than one-third of a million deaths in more than 200 countries worldwide. Early diagnosis of COVID-19 and management of complications is critical for better prognosis. In this regard, imaging modalities have played a vital front line role in diagnosis, grading of disease and monitoring the management course justifying its importance. Chest radiograph can detect patchy opacities and chest $\mathrm{CT}$ can appreciate multiple, peripheral ground-glass opacities and areas of consolidation. These findings are usually seen around bronchovascular bundle in the lung field. Although these findings are sensitive but not specific for COVID-19, CT chest has been vital in detecting early disease changes. ${ }^{[1]}$ These findings can change the management plan and isolate the patient appropriately. Due to the risk of spread, the CT scan machine must be disinfected after scanning every suspected COVID-19 patient.

To curb the spread of the disease, governments around the world have partially or completely shut down all non-essential services and implemented various measures. These measures have negatively impacted businesses, non-emergent healthcare provision, education, research and other aspects of life. As far as radiology is concerned, these measures have significantly reduced all imaging scans but outpatient volume has been severely reduced to $30-50 \%$ when compared with data from previous years. Additionally, following these guidelines all non-emergent outpatient imaging scans including ultrasound, radiographs, $\mathrm{CT}, \mathrm{MRI}$ and radiological interventional procedures have been rescheduled. ${ }^{[2]}$

Overall imaging volumes have dwindled to an all-time low. Due to reduced road traffic and fewer accidents, the volume of emergency scans has reduced worldwide. Additionally, stay-at-home orders and fear of exposure to COVID-19 from hospitals have played a deterring role causing the decreased volume of outpatient scans. This has impacted cancer patients follow up and routine cancer imaging too. Limitation on non-urgent imaging has caused the rescheduling of screening mammograms and lung cancer screening to prevent disease spread and enhance the dedicated facility for COVID-19 imaging. ${ }^{[2]}$ This will lead to a spike in demand for cancer screening in the near future once the pandemic is contained that needs to be addressed.

These measures have also affected the educational and research activities related to radiology. Due to the suspension of the normal routine and limited scans performed, many radiology trainees have been redeployed to do other tasks related to the current pandemic. Many hospitals during this pandemic are operating radiology using remote access or by staggering shifts. This has also impacted the trainee learning process. Similarly, many current or prospect research projects have been shut close either because of disruption of normal routine or due to uncertain fiscal situation and unavailability of funds. The lack of revenue and economic crisis caused by this pandemic has resulted in decreased or stopped funding for research projects.

The effects of this pandemic reach far beyond these aspects. Economically, this pandemic has detrimental effects and significant lost revenues have forced many small operations to temporarily salary reduction, reduce staffing, furlough employees or shut down operations altogether. According to a report, outpatient imaging services will be impacted the most and should expect a decrease in imaging volume to less than half at least for the next quarter year. ${ }^{[3]}$ This economic recession has caused a rise in global unemployment and limiting opportunities for locum or part-time radiologists. Furthermore, facility alterations to adjust to the new parameters set by COVID-19 guidelines have also increased expenditures.

Even after the pandemic is gone and behind us, we shall enter a new 'post-COVID era' and still feel its impact. We shall not be able to go back to our old routines possibly. The new normal will look completely different. This pandemic has fast-tracked innovation and redefined how we will run our operations in the future and new routines will be formed. Even during this COVID-19 era, radiology has seen an increasing trend towards safety precautions and safe environment, judicious use of imaging, remote access to scans, limited patient interaction, telemedicine 
for consultation with physicians and alteration to workflow routine.

In near term post-COVID-19 era, the biggest ramifications for radiological practice will be the economic impact. These will be determined mainly by the local magnitude of COVID-19 in any particular area, the time required towards normalcy, governmental policies, any subsequent second or third infective wave, time till any potential cure and vaccine is developed. This economic crunch will have a downstream effect. Millions of people have become unemployed and global economic depression has set in. This has led to the loss of insurance coverage for most non-urgent imaging scans and insufficient funds to cover pay out-of-pocket costs. This will eventually impact cancer screening and force people to not seek appropriate medical care at least temporarily. Physicians will also rely more on clinical judgment and be more cautious in their referrals. All these factors will decrease imaging revenue at least for 6-12 months. ${ }^{[4]}$

Historically, in similar circumstances, many small practices succumb to economic pressure and merge into larger healthcare practices.

Initial aftermath effects will include ensuring a safe environment for the patient and health personnel by improving departmental structure to reduce the risk of cross-infection by disinfecting all imaging equipment. Decontamination includes cleaning of patient contact areas with anti-microbial wipes and according to COVID-19 precautions. Additional measures are wearing protective equipment face masks, gloves and PPE for any interventional procedure, adding dedicated entrances for immunocompromised patients and introduction of a triage questionnaire to be filled by the patient to screen for COVID-19, any other infectious or contagious diseases so risk stratification can be done for the radiological examination. ${ }^{[3]}$ Additionally, advanced facilities can use negative pressure CT and MRI rooms for such patients.

Administrators need to be proactive with appropriate workplace modifications, cut overhead expenses and form lean operational routines so they can manage a sustainable economic position after the pandemic ends. They should consider opening the facility for extended hours, on weekends, expanding radiologist hours and scheduling staff in staggered shifts to accommodate the surge in demand for radiological imaging due to the backlog and previously rescheduled scans. This will ensure restoration of the reduced imaging volumes back to the baseline volumes before the pandemic. Maintaining appropriate staffing in the face of reduced revenues is critical for the smooth functioning of radiology practice. To ensure the provision of extended hours radiological services, modification of workplace and ease of remote access is also vital. Facilities need to innovate and build infrastructure to accommodate the off-site workforce. They need to enhance hardware facilities, PACs and telehealth capacity for interpretation of diagnostic scans remotely. Although these changes will importantly affect junior radiologist and trainee learning, measures can be taken to reduce any gaps in communication by facilitating e-learning and online classes. In short, this post COVID-19 era will transform our way of working, learning and thinking perhaps for the better.

Waqas Ahmad, Usman Ahmad Shaukat Khanum Memorial Cancer Hospital and Research Center, Lahore, Pakistan. E-mail: waqasrad@gmail.com

\section{References}

1. Yang W, Sirajuddin A, Zhang X, Liu G, Teng Z, Zhao S, et al. The role of imaging in 2019 novel coronavirus pneumonia (COVID-19). Eur Radiol 2020:1-9. doi: 10.1007/s00330-020-06827-4.

2. ACR COVID-19 clinical resources for radiologists. American College of Radiology. 2020. Available from: https://www.acr. org/Clinical-Resources/COVID-19-Radiology-Resources. [Last accessed on June 2020].

3. Luker GD, Boettcher AN. Transitioning to a new normal after COVID-19: Preparing to get back on track for cancer imaging. Radiol Imaging Cancer 2020;2. doi: 10.1148/rycan.2020204011.

4. Cavallo JJ, Forman HP. The economic impact of the COVID-19 pandemic on radiology practices. Radiology 2020:201495. doi: 10.1148/radiol.2020201495.

This is an open access journal, and articles are distributed under the terms of the Creative Commons Attribution-NonCommercial-ShareAlike 4.0 License, which allows others to remix, tweak, and build upon the work non-commercially, as long as appropriate credit is given and the new creations are licensed under the identical terms.

\begin{tabular}{|l|l|}
\hline \multicolumn{2}{|c|}{ Access this article online } \\
\hline Quick Response Code: & \\
\hline & $\begin{array}{l}\text { Website: } \\
\text { www.ijri.org }\end{array}$ \\
& DOI: \\
\hline
\end{tabular}

Cite this article as: Ahmad W, Ahmad U. Role of radiology in COVID-19 pandemic and post COVID-19 potential effects on radiology practices. Indian J Radiol Imaging 2021;31:S196-7.

Received: $25-J u n-2020$

Revised: 11-Jul-2020

Accepted: 06-Jul-2020 